\title{
Violência e negociação na construção da ordem nas prisões: a experiência paulista
}

Recebido: 08.07.18 Aprovado: 04.03 .19

\section{Camila Nunes Dias* \& Fernando Salla**}

Resumo: 0 artigo discute a construção da ordem nas prisões a partir do referencial teórico da sociologia das prisões e de um contexto empírico muito específico: o cenário paulista, marcado pela hegemonia do grupo Primeiro Comando da Capital (PCC). Nosso argumento é que esse grupo reconfigurou a dimensão da ordem nas prisões; enquanto organização, estabeleceu um novo padrão de relações com a administração prisional; redesenhou as formas de exercício do poder no interior da massa carcerária, tanto em termos dos elementos constitutivos das hierarquizações entre os presos, como dos controles sociais e, ainda, do uso da violência. Além de um diálogo com a literatura voltada para o tema, foram tomados como objeto de análise dois documentos produzidos pelo PCC (estatutos) que refletem dois momentos distintos da trajetória do grupo, cada um deles engendrando elementos e mecanismos que alteraram as dinâmicas na construção da ordem prisional.

Palavras-chave: Prisões. Primeiro Comando da Capital (PCC). Estatutos PCC. Ordem prisional. Legitimidade.

\section{Violence and negotiation in the construction of order in prisons: the São Paulo's experience}

Abstract: The article discusses the prison order from the sociology of the prisons theoretical reference and also from a very specific empirical context: the São Paulo scenario, marked by the hegemony of the Primeiro Comando da Capital (PCC) group. Our argument is that this group reconfigured the prison order; as an organization, established a new pattern of relations with the prison administration; it designed new forms of power exercise within the prison population, in terms of both the elements of prisoners' hierarchies, as well as social controls and use of violence. In addition to the literature focused on the theme, two documents produced by the PCC (statutes) were taken as object of analysis that reflect two distinct moments of the group's trajectory; each one engendering elements and mechanisms that changed the dynamics while producing prison order.

Keywords: Prison. Primeiro Comando da Capital (PCC). PCC's statutes. Prison order. Legitimacy.

\author{
* Camila Nunes \\ Dias é professora da \\ Universidade Federal \\ do $A B C$ (UFABC) e \\ pesquisadora do \\ Núcleo de Estudos \\ da Violência da \\ Universidade de São \\ Paulo (NEV-USP), \\ Santo André, São \\ Paulo, Brasil. \\ Orcid: 0000-0002- \\ 8389-3830. \\ <camila.dias00@ \\ gmail.com>. \\ ** Fernando Salla \\ é pesquisador \\ associado do \\ Núcleo de Estudos \\ da Violência da \\ Universidade de São \\ Paulo (NEV-USP). \\ São Paulo, São Paulo, \\ Brasil. \\ Orcid: 0000-0002- \\ 3302-4573. \\ <fersalla@gmail. \\ com>.
}




\section{Introdução}

O presente artigo discute a construção da ordem nas prisões, a partir das reflexões acadêmicas desenvolvidas na área das ciências sociais. Autores clássicos, como Sykes (1974), Goffman (1974) e Clemmer (1958) dedicaram parte de seus estudos na compreensão das múltiplas dimensões das interações sociais entre os internos, entre internos e custodiadores, processos esses que levavam ao estabelecimento da ordem em locais de confinamento dos indivíduos.

A vasta literatura internacional que se formou sobre as prisões, no último quartel do século XX, direta ou indiretamente tratou da questão da manutenção da ordem nas prisões, bem como dos fatores que poderiam provocar sua ruptura (King, 1990; Useem \& Kimball, 1991; Dilulio Jr., 1990; Sparks \& Bottoms, 1995). A recolocação da prisão no centro das punições nesse período, a escalada do encarceramento, a falência dos ideais de reabilitação, a presença cada vez mais intensa do gerencialismo no debate sobre a condução dos espaços punitivos são elementos que colocaram em destaque os novos desafios apresentados com a falência do welfarismo penal.

Desse novo cenário, de um lado, fazem parte os novos modelos de organização prisional (como as supermax ou as unidades especiais) destinados a conduzir o cotidiano prisional quase que prescindindo dos valores ressocializadores que então predominavam nas políticas penais. Radicalizaram-se os dispositivos de controle, de isolamento, internamento e também em relação à sociedade. De outro lado, entraram em cena as gangues, as facções, os grupos de presos que passaram a ter controle maior ou menor sobre a massa carcerária, impondo suas regras de convívio, pactuando novas relações de poder com os custodiadores. Muitos desses grupos são oriundos das ruas, dos bairros populares, e levam para a prisão suas formas de identidade étnica, racial ou religiosa, como, por exemplo, em muitas prisões norte-americanas (Jacobs, 1977). Com isso, intensificaram-se as circulações, as conexões entre o interior das prisões e as áreas de onde são provenientes os integrantes dessas facções, desses grupos, dessas gangues.

Como discutiremos adiante, os vínculos familiares, as relações de solidariedade produzidas nas atividades ilegais, mas, sobretudo, os negócios ilegais mantidos dentro e fora das prisões ativam o fluxo dessas interações (Godoi, 2018). Que tipo de ordem vem sendo produzida nas prisões em que os grupos exibem sua capacidade de ditar regras para seus membros, mas também de estabelecer um conjunto de protocolos (muitos dos quais são documentos escritos, no caso, aqui, em análise) para 
a convivência com outros grupos, com os custodiadores? Como as administrações prisionais lidam com a presença desses grupos, como se pactua a ordem entre essas esferas de poder, constituído e extralegal? Tais questões vêm estimulando diversos estudos como os de Sacha Darke (2013; 2014), David Skarbek (2012; 2016), Camila Dias e Fernando Salla (2013), dentre outros.

A presente análise é a continuidade de reflexões anteriores (Alvarez et alii, 2013) e um dos resultados de pesquisa realizada entre 2013 e 2016 . Esse estudo envolveu a coleta de documentos oficiais sobre o Primeiro Comando da Capital (PCC) - notadamente, inquéritos policiais, denúncias do Ministério Público Estadual, sentenças e processos judiciais - e de documentos elaborados pelos próprios membros do

1. Pesquisa financiada pelo CNPq, no âmbito do edital Universal/2013. grupo, tais como estatutos, cartilhas, salves, cartas. Esses últimos documentos circulam entre os membros do PCC e, às vezes, entre pessoas próximas (outros presos, familiares, amigos etc.), o espaço de circulação depende, evidentemente, do teor e objetivo da mensagem que pode ser uma diretriz ou uma ordem restrita aos integrantes do grupo ou ainda uma mensagem de caráter mais geral, destinada às famílias, à população carcerária ou à sociedade em geral. A documentação vem sendo coligida desde 2013 e a partir desta foi organizado um banco de informações que continua sendo regularmente alimentado.

Além desses documentos, a discussão proposta está assentada também em entrevistas com presos, autoridades (juízes, promotores), agentes penitenciários, advogados e policiais (militares, civis, federais) desenvolvidas ao longo de vários projetos de pesquisa (ver, por exemplo, Dias, 2013; Manso \& Dias, 2018; Adorno \& Salla, 2007; Salla, 2006) cada um dos quais abordando aspectos diferentes da dinâmica prisional, da atuação das facções criminais dentro e/ou fora das prisões, especialmente na conformação das economias ilegais nas regiões urbanas e nas fronteiras. A partir deste acúmulo de pesquisas e de material coletado, propomos aqui uma discussão específica envolvendo a construção da ordem nas prisões, tomando como ponto de referência empírico da análise dois documentos específicos:

i. o Estatuto do PCC, escrito e disseminado entre a população carcerária por volta de 1997;

ii. o Estatuto do PCC, de 2011, quando o PCC completou 18 anos de existência.

A produção de registros escritos no âmbito da gestão do poder efetivada pelo PCC dentro - e fora - das prisões é um aspecto importante das mudanças engendradas por este grupo no que concerne à sua capacidade de manter a ordem das prisões. 
2. Nosso foco está principalmente num ator coletivo, mas uma chave também possível de análise seria explorar as dimensões individuais, subjetivas da desordem, da revolta e como elas podem se articular ou mesmo nutrir os movimentos coletivos.
Neste sentido, a despeito da extensa literatura sobre a produção da ordem nas prisões e sobre o PCC em São Paulo, os documentos produzidos pelo grupo ainda não foram objetos de análise específica e aqui se situa a principal contribuição deste trabalho no âmbito deste campo de estudos.

Estudos clássicos sobre os ambientes prisionais no Brasil anteriores à década de 1990 - como Ramalho (1979), Coelho (1987) -, ou trabalhos de jornalistas - como Souza $(1977$; 1983) - mostram que foram muitas as transformações que ocorreram nas prisões desde então. Dentre elas, a ordem prisional passou a ter novos arranjos. Nosso argumento é que o PCC reconfigurou a dimensão da ordem nas prisões; enquanto organização, redesenhou as formas de exercício do poder no interior da massa carcerária, tanto em termos dos elementos constitutivos da hierarquia entre os presos, como dos controles sociais e, ainda, do uso da violência. A emergência desse grupo significou também um novo padrão de relações com a administração prisional (Alvarez et alii, 2013; Dias, 2009; 2013).

No curso de nossa reflexão, consideraremos ordem prisional a situação de um relativo equilíbrio entre presos e custodiadores, a partir das referências clássicas indicadas na análise feita por Sykes (1974). Pode haver ordem mesmo quando há tensões constantes no ambiente prisional; mesmo quando as relações de poder são assimétricas, ocorrendo uma forte centralização e controle por parte dos custodiadores ou, então, um amplo exercício de poder por parte de gangues e grupos organizados de presos. A desordem é a ruptura do equilíbrio nas relações entre presos e custodiadores, aquilo que desarticula o funcionamento da prisão, provocando a não aceitação dos papéis recíprocos; é a fratura dos acordos formais e informais que dirigem minimamente o cotidiano prisional; é a revolta, a rebelião, a violência como silenciamento dos acordos, a instabilidade e a imprevisibilidade ${ }^{2}$.

Em suma, a ordem prisional não significa a supressão das tensões, dos conflitos, das disputas, desde que sejam acomodados numa pactuação "legitimada" de regras formais e informais entre presos, entre grupos de presos e custodiadores. As disputas em torno do estabelecimento da ordem, por parte dos grupos de presos, de um lado, e por parte dos custodiadores, de outro, mesmo tendo esses o estatuto legal a seu lado, remetem, portanto, à questão da legitimidade e de suas implicações para o ambiente prisional (Sparks \& Bottoms, 1995; Jacobs, 1977).

Inserir a experiência paulista neste campo de reflexões, considerada sob o prisma específico da análise dos dois estatutos do PCC, permite colocar no debate clássico sobre a construção da ordem nas prisões novas questões e tensionamentos que se tornam mais complexos, ao passo que as dinâmicas prisionais se articulam 
cada vez de maneira mais estreita com as dinâmicas políticas e criminais externas aos espaços prisionais. Neste sentido, a análise dos estatutos permite aprofundar o debate, colocando em primeiro plano a configuração das redes de poder nos espaços das prisões.

\section{Caminhos de análise}

Para Mathiesen (1966) os temas prisionais a serem pesquisados precisam ter relevância teórica e importância social para que avanços sejam alcançados nesse campo específico de pesquisa. Sustentamos que a presença do fenômeno PCC no universo prisional paulista - e o surgimento de diversos grupos nas prisões brasileiras - traz para as análises sociológicas sobre as prisões desafios teóricos em relação à literatura já existente. Considere-se, nesse sentido, o desafio de analisar os processos sociais identitários que permitiram a formação de tais grupos e a recomposição das relações de poder tanto na linha horizontal, com o restante da massa carcerária, como no plano vertical, em relação aos agentes diretos da custódia. O fenômeno PCC apresenta, ao mesmo tempo, relevância do ponto de vista social e político, uma vez que dinâmicas criminais contemporâneas têm sofrido a sua influência e têm contribuído para aumentar as pressões para a adoção de medidas na perspectiva do endurecimento penal.

Assim, Mathiesen (1966) - ao buscar levar as análises sociológicas sobre as prisões para um patamar de maior adensamento - indica a necessidade de redefinir as articulações e os tensionamentos entre os aspectos formais e informais que configuram as prisões. Se nos estudos sociológicos sobre as prisões, muitas vezes, foram valorizadas as análises que colocaram em evidência os aspectos informais que estão presentes nesses ambientes - a exemplo de Clemmer (1958), Sykes (1974), Goffman (1974), dentre outros -, a formação e atuação do PCC se constitui um caso emblemático para se compreender a importância dessa dimensão na construção da ordem nas prisões brasileiras e a dinâmica prisional em sentido mais amplo. Porém, a própria compreensão da centralidade adquirida pelos elementos informais na construção da ordem prisional só é possível se consideramos os aspectos formais que acabam por configurar o contexto prisional. Os aspectos formais e informais da prisão estão articulados entre si, tensionando-se ou reforçando-se mutuamente. Nesse sentido, embora o PCC tenha se originado no ambiente prisional, em composições, alianças e dinâmicas inerentes à "sociedade dos cativos" (Sykes, 1974), ou seja, como elemento resultante de uma "cultura prisional" (Clemmer, 1958), não se pode perder de vista o contexto histórico-político de sua emergência (Jacobs, 1977). 
3. Ver, por exemplo, a descrição feita por Jacobs (1977) do processo de transformação social e institucional ocorrido na Penitenciária de Stateville, a partir da penetração dos discursos e das práticas sociais e políticas que marcaram a sociedade norteamericana na década de 1960.

\footnotetext{
4. Para uma discussão acerca da legitimidade da atuação do PCC nos territórios urbanos de São Paulo, ver Ruotti (2016).

5. Holston (2009), de certa forma, também explora essa dimensão de apropriação do discurso dos direitos pelos grupos pertencentes ao mundo do crime.
}

Num ambiente de redemocratização do país, desde meados da década de 1980, eleva-se o debate sobre os direitos dos presos e promulga-se a Lei de Execução Penal (Teixeira, 2009); políticas de humanização dos presídios colocaram em pauta a necessidade da redução da violência e das arbitrariedades dos agentes do Estado, a necessidade do respeito à lei e responsabilização dos agressores (Góes, 2009; Alvarez et alii, 2013). Esse ambiente de promoção e proteção aos direitos oscilava e, paradoxalmente, se conjugava com retrocessos nas políticas penais e na ação do Estado dentro das prisões expressos em eventos paradigmáticos como o "caso do 42 DP" e o "massacre do Carandiru" (Salla, 2007), ápice de uma política de construção da ordem prisional a partir da intervenção estatal extremamente violenta e arbitrária.

Não é casual, portanto, que a criação do PCC seja datada em 1993 (Teixeira, 2009; Dias, 2013; Jozino, 2008), nesse contexto de avanços legais e institucionais em relação ao funcionamento das prisões e, ao mesmo tempo, uma escalada de ações violentas por parte dos agentes do Estado. Importante mencionar aqui o quanto os movimentos pelos direitos civis são apontados como importante influência sobre as tensões e as rupturas ocorridas na década de 1960 nas prisões norte-americanas ${ }^{3}$. No caso do PCC, é justamente através de denúncias de violências múltiplas na prisão e da violação sistemática de direitos dos presos pelo Estado que busca dar suporte ao seu discurso e às novas propostas de relações que traz à população carcerária. Ou seja, o PCC vai buscar legitimar seu poder e influência sobre a massa carcerária alceando a bandeira dos direitos que sistematicamente são violados (Dias, 2013; Alvarez et alii, 2014); vai buscar a denúncia de tais violações estabelecendo contatos, enviando cartas para organismos e organizações governamentais e não governamentais (Teixeira, 2009).

Em suma, a constante violação de direitos nas prisões brasileiras é a base a partir da qual se ancora a pretensão de legitimidade do $\mathrm{PCC}^{4}$ diante da população carcerária, num esforço de articular um discurso de união entre os presos como forma de enfrentamento ao Estado, reputado opressor e injusto. Nesse sentido, o PCC pode ser considerado um caso radical de cultura prisional que combina e se articula aos elementos formais que pautam o domínio das políticas penais, das instituições de controle social, em particular a polícia e as prisões 5 .

A trajetória do PCC no sistema prisional requer, assim, uma análise que combine a dimensão informal de sua composição no ambiente prisional e criminal com o próprio contexto de extensão das garantias legais advindas na esteira da democratização brasileira desde os anos 1980 que, mesmo sendo sistematicamente desrespeitadas, servem de elemento articulador de suas ações tanto nos litígios 
com as autoridades como na busca de lastro de legitimidade para o grupo junto à massa carcerária.

De certa forma, o fenômeno ocorrido nos estados brasileiros com maior população prisional na década de 1980 (Rio de Janeiro ${ }^{6}$ e São Paulo) em parte se aproxima do que ocorreu em muitas prisões norte-americanas a partir da década de 1950, em que parcela da população carcerária foi profundamente influenciada pelo movimento pelos direitos civis que ganhava força no país, produzindo uma inédita politização da massa carcerária, notadamente das minorias étnicas e raciais (Jacobs, 1977). Conforme o autor destaca, as prisões são diretamente influenciadas por movimentos e demandas sociais e políticas específicas provenientes da sociedade mais ampla. Neste sentido, o movimento para ampliação dos direitos civis provocou um aumento da expectativa e das demandas por democratização das prisões ao mesmo tempo que as condições internas, em si mesmas, não poderiam corresponder a essas expectativas. Este gap entre expectativas e condições concretas das prisões acabou por erodir a autoridade local, assentada no autoritarismo, abrindo um vácuo que levou a uma profunda instabilidade e à ruptura da ordem interna ${ }^{7}$.

Dessa forma, melhor seria compreendido o PCC a partir da combinação das duas dimensões - a informal e a formal -, evitando-se o unilateralismo tanto das abordagens microssociais e locais como o formalismo da leitura dos estatutos jurídicos que se voltam para o crime e a punição. Subjacente a esse tipo de análise se coloca a presença da ação do Estado e de seus representantes para compreender a sua relação com o mundo do crime e as interferências diretas e indiretas que exerceram sobre o próprio PCC.

Mathiesen (1966) também observa que é necessário que as análises considerem as diferenças existentes entre as unidades prisionais. A presença do PCC tem sistematicamente provocado um tratamento mais acurado das análises sociológicas sobre aquelas diferenças, uma vez que parece bastante singular a experiência de formação e projeção do PCC em São Paulo em relação às prisões de outros estados brasileiros.

Vários aspectos permitem delinear as especificidades das prisões de São Paulo em relação às unidades de outros estados. Por exemplo, a herança de violência presente no sistema com unidades prisionais como a Casa de Detenção de São Paulo e o Anexo da Casa de Custódia de Taubaté (Teixeira, 2009; Salla, 2006); o contexto de um encarceramento massivo no estado de São Paulo atingindo, em 2017, a marca dos 230 mil presos ${ }^{8}$, representando a terça parte da população carcerária

6. Para a descrição e análise do que ocorreu no Rio de Janeiro, com a criação das Comissões Internas de Prevenção de Acidentes (Cipa) durante o governo Leonel Brizola, ver Coelho (1987).

7. A pesquisa de James B. Jacobs ocorreu na

Penitenciária de Stateville, estado de Illinois. Mas, entre os anos 1950 e 1960, movimentos, motins e rebeliões se espalharam por prisões em vários locais dos Estados Unidos, provocando uma ampla reflexão sobre o sistema prisional do país (Sykes, 1974; MacCormick, 1954).

8. Conforme dados da Secretaria da Administração Penitenciária do Estado de São Paulo (SAP-SP), disponível em <http://www. sap.sp.gov.br/sapdados/estatisticas. html\#top $>$. Acesso em: 05 Mar. 2019. 
9. Não será possível retomar aqui este processo. Para mais informações sobre os elementos que estão vinculados ao processo de expansão do PCC nas prisões paulistas, ver Dias (2013), Salla (2008), Adorno \& Salla (2007).

10. Não há trabalhos acadêmicos que ofereçam um panorama nacional e sistemático da presença do PCC nas prisões brasileiras. Há apenas estudos específicos, dados e informações esparsos e fragmentados. A esse respeito, ver: $<$ http://www.bbc. com/portuguese/ brasil-37663153>. Acesso em: 04 Nov. 2016.

11. Entrevista realizada em julho de 2016 na Penitenciária Estadual de Dourados. brasileira (Dias et alii, 2015); a extensão e a capilaridade da rede carcerária no Estado (Silvestre, 2012); as ambíguas intervenções no plano administrativo e no tratamento penal, que vão do endurecimento e rigor disciplinar às disposições e programas de reabilitação social do criminoso, bem como os acordos e acomodações com os grupos organizados (Dias, 2009; 2013). Outros aspectos "locais" ainda poderiam ser adicionados, como a existência de presos providos de grande capacidade intelectual, de planejamento e de habilidade discursiva, persuasiva e de negociação. Tais especificidades permitem também compreender as dinâmicas prisionais que levaram à condição hegemônica do PCC $^{9}$.

Enfim, se o sistema prisional paulista ofereceu as condições que permitiram o surgimento do PCC, o próprio processo de sua expansão no sistema prisional paulista, especialmente a partir da hegemonia alcançada, produziu amplas transformações na dinâmica das prisões de São Paulo. Conforme pode ser observado a partir de documentos coletados e de entrevistas realizadas com presos em São Paulo e em outras unidades da Federação, a hegemonia do PCC produz uma dinâmica prisional sui generis que leva as prisões paulistas apresentarem uma configuração diferente das prisões dos demais estados. A compreensão do fenômeno da construção da ordem prisional - a partir da hegemonia do PCC - deve partir de especificidades que permitiram o seu surgimento e, ao mesmo tempo, deve considerar as eloquentes transformações que ele mesmo produziu neste contexto. O PCC é, nesse sentido, produto e produtor de especificidades na dinâmica das prisões de São Paulo.

Mas não se deve considerar que a presença do PCC se restrinja às unidades prisionais de São Paulo. Como diversas pesquisas recentes vêm demonstrando (Dias, 2017; Manso \& Dias, 2017, 2018; Feltran, 2018), em diversos estados brasileiros as unidades prisionais vêm sendo marcadas por sua atuação direta ou em aliança com grupos locais. Contudo, a forma, a expressão e o grau de influência do PCC nas dinâmicas das prisões Brasil afora variam bastante de estado para estado, bem como entre as unidades prisionais num mesmo estado. Não há homogeneidade e há configurações bastante diferenciadas em cada estado da Federação ${ }^{10}$.

Neste sentido, cabe aqui sublinhar a especificidade paulista no que tange à presença do PCC nas prisões. O "crime é mais evoluído em São Paulo", afirmou um membro do PCC que, apesar de ser paulista, cumpria pena no Mato Grosso do Sull ${ }^{11}$. A "evolução do crime" remete justamente à maior estabilidade da ordem prisional (e, também, fora das prisões) construída e mantida mediante as normas e regras que fazem parte da "disciplina do PCC" - e que, apesar de ser a mesma em todos os 
locais nos quais estão presentes seus integrantes, assumiu características peculiares em São Paulo. A extensão, a durabilidade e a estabilidade de sua hegemonia no sistema prisional de São Paulo permitiram uma reconfiguração mais profunda das dinâmicas do cárcere, uma transformação da sociabilidade entre os presos e na relação da massa carcerária com a administração prisional. Houve um deslocamento na construção da ordem nas prisões e a principal característica deste deslocamento reside em seu aspecto "sistêmico".

A farta documentação produzida em relação ao PCC registra e solidifica um corpo normativo e prescritivo próprio. É, ao mesmo tempo, efeito de sua consolidação e condição de fortalecimento de sua hegemonia. As normas (estatutos e cartilhas), as decisões (comunicadas através de "salves"), os controles financeiros (planilhas de controle de débitos e créditos), logísticos (mercadorias), de pessoal (cadastro dos integrantes e de sua situação na organização quanto às obrigações assumidas) e disciplinares (relatórios) se constituem elementos específicos do controle exercido pelo PCC nas prisões - e fora delas. São fundamentais para a compreensão de sua capacidade de produção da ordem prisional através da adoção de procedimentos duráveis e estáveis, passíveis de serem transmitidos e retransmitidos, ratificados, retificados ou transformados. A despeito de serem mencionados em alguns trabalhos, há uma lacuna no campo de pesquisas sobre o tema no que tange a esses registros, tanto no que se refere à reflexão sobre o significado e os efeitos dessa produção regular e sistemática, quanto à análise dos conteúdos destes diferentes tipos de documentos.

Uma vez consolidada a hegemonia do PCC nas prisões paulistas nos anos 2000, a possibilidade de ocorrência de ruptura da ordem nas prisões de São Paulo assumiu um aspecto "sistêmico". Um dos pontos centrais da estabilidade sistêmica está associado ao fato de as principais lideranças desse grupo terem sido reunidas e cumprirem penas em algumas unidades prisionais em São Paulo. Essa condição parece ser o elemento fundamental que pactua informalmente uma ordem no conjunto do sistema prisional paulista. Assim, tendo o PCC o controle da quase totalidade das prisões e sendo a gestão local dos presos diretamente vinculada às diretrizes e às decisões que se dão no âmbito da sua cúpula, uma eventual ruptura das relações entre o PCC a administração prisional poderia provocar desequilíbrio no sistema como um todo ${ }^{12}$. O último evento que expressou essa dinâmica foram os chamados "Ataques de maio de 2006" (Adorno \& Salla, 2007). A construção da ordem no espaço prisional em São Paulo tem se efetivado não apenas através de processos, relações e interações que se produzem localmente, no espaço das unidades prisionais, mas, sobretudo, através de relações sociais e políticas, de
12. Houve uma alteração nesta configuração com a transferência de alguns presos apontados pelas autoridades como pertencentes à cúpula do PCC para o Sistema Penitenciário Federal. Desde o anúncio da possibilidade da transferência até a sua efetivação, entretanto, passaram-se quatro meses. Consideramos que foi tempo suficiente para que outra arquitetura de poder e garantia da ordem fosse construída de forma a não interromper a dinâmica econômica e política de funcionamento do PCC, dentro e fora das prisões.

As possíveis reações de PCC foram fartamente discutidas na imprensa e também pelas autoridades. Consideramos que, neste momento, é bastante inverossímil. Para uma discussão a respeito, ver: <https:// todavialivros.com.br/ visite-nossa-cozinha/ a-transferencia>. Portanto, esse acontecimento em nada altera as discussões propostas neste texto. 
13. Essa

configuração

não elimina, evidentemente, os conflitos locais, as microdisputas entre os presos e o staff prisional. Mas essas tensões ficam contidas, não transbordam para o plano de uma ruptura da ordem prisional. diretrizes de ação, de narrativas e como produtos decorrentes de relações que se efetivam para além das especificidades locais das unidades prisionais e mesmo para além das próprias prisões, tal como se viu em 2012 (Dias et alii, 2015a) ${ }^{13}$.

A hegemonia do PCC em São Paulo permitiu, portanto, a construção e a manutenção da ordem nas prisões numa perspectiva sistêmica e que, por isso mesmo, essa se apresenta de forma muito mais estável do que em outros estados (haja vista o número reduzido de eventos de motins ou rebeliões) mas, ao mesmo tempo, com a potencialidade de produzir a ruptura do sistema como um todo (Dias, 2013). Paradoxalmente, parece ser esse aspecto sistêmico que permite a ameaça à segurança do Estado e que, por isso mesmo, se torna mais estável, uma vez que abre espaço para múltiplas formas diretas e indiretas de articulações envolvendo o PCC e os atores estatais situados em diferentes posições institucionais (Dias, 2009).

Outro ponto sugerido por Mathiesen (1966) para uma análise mais densa das prisões é considerar os processos de mudança que alcançam esses locais. É um equívoco considerar as prisões como sistemas fechados, autorregulados e que, portanto, tendem a permanecer estáticos, perspectiva essa que marcou um ciclo de análises clássicas (Clemmer, 1958; Sykes, 1974; Goffman, 1974). Da mesma forma que as prisões apresentam diferenças entre si, é igualmente fundamental atentar para as mudanças ocorridas nas prisões como forma de compreender os desafios que elas colocam não apenas para o poder público, como também para as análises no campo da própria teoria social. As muitas formas de transação das práticas prisionais com a sociedade abrangente, a porosidade de seus muros, revelando a circulação de ideias, linguagens, comportamentos e práticas em geral, entre o dentro e o fora, redefinem aquelas análises clássicas (Adorno \& Dias, 2017; Godoi, 2017).

Com a presença do PCC no cenário prisional, mudanças emergiram: novas práticas de segurança por parte do staff, novas formas de relacionamento entre os presos a partir de padrões impostos pelo PCC de proteção e de exigência de lealdade; alteração na organização mesma das prisões em relação aos objetivos de segurança e de ressocialização. Destaca-se, ainda, a criação de unidades prisionais de "regime especial", híbrido ou intermediário - entre o regime comum da grande maioria das unidades prisionais e a unidade em que se aplica o Regime Disciplinar Diferenciado (RDD) - que, embora sejam formalmente classificadas como unidades de regime comum, funcionam como unidades especiais, destinadas justamente a abrigar os presos identificados como lideranças do PCC (Salla et alii, 2012). 
Um dos pontos mais salientes das mudanças no sistema prisional é a radicalização de medidas e de procedimentos adotados no plano da administração voltados para a gestão da segurança (Dias, 2013). Esse conjunto de medidas envolve, em primeiro lugar, mudanças na estrutura física das unidades, como a criação de unidades menores, com espaços coletivos reduzidos; nas unidades mais antigas, divisão dos espaços coletivos - especialmente o pátio, para banho de sol - para reduzir a convivência dos presos; automatização das portas das celas. Importa, ainda, a adoção de outros procedimentos de rotina no interior das prisões, como, por exemplo, o funcionário não mais permanecer dentro do raio ou no pátio de sol; a organização e a distribuição de medicamentos, alimentação e quaisquer outros materiais para a população prisional efetuada pelos próprios presos, entre outras medidas. Há uma clara interferência das facções na definição de quem ocupa qual posto de trabalho ${ }^{14}$. Em terceiro lugar, estão as medidas administrativas que, inequivocamente colidem com disposições legais, como a adoção de castigos ou punições disciplinares coletivas em casos específicos, como agressões a funcionários; ou, então, a definição de incluir ou não alguém no RDD ou numa unidade prisional do sistema federal, além do tempo de permanência nestes regimes, que sofre a injunção de questões políticas e administrativas nem sempre com observância das prescrições constitucionais.

Dentre os efeitos produzidos por esse conjunto de mudanças - apresentamos apenas alguns exemplos aqui -, destacamos a radical separação e segregação entre presos e funcionários, apoiada, sobretudo, pela adoção de tecnologias que permitem restringir ao máximo o contato entre eles ${ }^{15}$.

\section{A produção da ordem}

Dentre o grande volume de documentos produzidos no âmbito do PCC, destacamos para a análise aqui proposta dois documentos importantes, denominados de estatutos, que podem sugerir algumas pistas para compreender várias questões relacionadas à produção da ordem nas prisões e à legitimidade que parece ser reiteradamente reivindicada pelo grupo enquanto "representante" da população carcerária ${ }^{16}$. Os estatutos são conjuntos de normas de conduta e atuação, bem como de prescrições e orientações éticas e morais. Ao contrário dos "salves", são perenes, ou seja, constituem-se como a pedra angular dos princípios que regem o pertencimento e a relação política, moral, ética ou econômica no âmbito da organização. É a partir do estatuto que outras diretrizes são instituídas ou decisões são tomadas. Em analogia com o nosso sistema legal, o estatuto estaria numa posição similar à da Constituição Federal.
14. Com exceção dos casos em que os presos que trabalham permanecem em pavilhões ou celas separadas da população carcerária - justamente para evitar que sejam alvos de pressões para atender a demandas das facções. Isso é comum quando os presos trabalham em setores da administração da unidade e, portanto, têm maior proximidade com funcionários e diretores e permanecem parte do dia em região bem próxima dos acessos ao exterior da unidade.

15. Um exemplo emblemático neste sentido é a automatização das portas das celas das unidades prisionais de São Paulo. Embora não tenhamos dados que apontem com precisão quantas unidades prisionais já estão equipadas com essa tecnologia, sabe-se que a meta da administração prisional e estender esse procedimento a todas as unidades prisionais.

16. Vale lembrar que o PCC - e os demais grupos similares existentes no Brasil - produz de forma rotineira, documentos que são chamados de "salves" e cujo objetivo central é a 
comunicação entre os integrantes, recados/avisos de um grupo para outro, ordens, ameaças, informações etc.
Como se observou acima, a formação do PCC pode ser colocada como desdobramento de uma tendência de endurecimento das políticas na área da segurança pública que ocorreu depois do governo Montoro (1983-1986) e que se expressou em acontecimentos como a forte repressão aos presos numa rebelião na Penitenciária do estado, em 1987 (com 28 mortos); as mortes de presos no 42음 Distrito Policial (18 por asfixia), em 1989; o Massacre do Carandiru (111 mortes), em 1992; bem como a manutenção de condições severas de encarceramento em geral existentes nas prisões paulistas, principalmente no Anexo da Casa de Custódia de Taubaté. E foi exatamente nessa unidade prisional que surgiu, em 1993, o PCC. Dentre os efeitos dessa dimensão repressiva na produção da ordem nas prisões, associada às rotineiras condições degradadas de encarceramento, estão os baixos níveis de reconhecimento, entre os presos, da legitimidade dessa ordem. O fato mesmo de o PCC ter sua origem no Anexo da Casa de Custódia de Taubaté é significativo, pois ali o severo regime disciplinar com amplas limitações para os presos em termos de mobilidade espacial e tratamento penal, sempre tornou a ordem muito mais o resultado de processos coercitivos (Teixeira, 2009) do que de práticas e crenças compartilhadas que pudessem dar-Ihe um lastro de legitimidade.

Apesar de a formação do PCC datar de 1993, o primeiro estatuto do grupo só teria aparecido alguns anos depois, por volta de 1997, e apresenta características que o aproxima de outros conjuntos de regras de grupos similares (Jacobs, 1974). A elaboração desse estatuto revela uma preocupação em estabelecer um regramento para os membros do grupo e também para a vida carcerária. É um documento que aponta para a crença em torno dos dispositivos legais que normatizam a organização e o funcionamento das prisões, mas, ao mesmo tempo, apresenta uma posição de enfrentamento com as autoridades em torno de seu fracasso em assegurar um cotidiano prisional compatível com aqueles dispositivos (Alvarez et alii, 2013). O estatuto permite, ainda, compreender os discursos e os valores que são mobilizados na conformação de um sentimento de pertencimento, coesão e unidade, elementos que serão essenciais para a compreensão do desenvolvimento do PCC. Não é possível dar conta, neste espaço, da análise de todos os itens arrolados nos estatutos. Contudo, faremos uma discussão analítica daqueles itens que mais fortemente remetem à compreensão das dinâmicas de construção da ordem nas prisões.

Em seu terceiro item, o estatuto indica um dos lemas do grupo: "A união da luta contra as injustiças e a opressão dentro das prisões". A posição de denúncia e de enfrentamento às autoridades em face da violência presente nas prisões fica ainda mais evidente nos itens 13 e 14. Tais itens tocam na questão central de uma ordem prisional tirânica que era característica do Anexo da Casa de Custódia de 
Taubaté, o que se constituirá na principal base de legitimação do ideológica do PCC, até os dias atuais. O PCC vai ter como uma de suas principais reivindicações a desativação do anexo, unidade de contenção disciplinar na qual a ordem era mantida sob forte regime de ameaça e coerção:

13. Temos que permanecer unidos e organizados para evitarmos que ocorra novamente um massacre semelhante ou pior ao ocorrido na Casa de Detenção em 2 de outubro de 1992, onde 111 presos foram covardemente assassinados, massacre este que jamais será esquecido na consciência da sociedade brasileira. Porque nós do Comando vamos mudar a prática carcerária, desumana, cheia de injustiças, opressão, torturas, massacres nas prisões.

14. A prioridade do Comando no montante é pressionar o governador do estado a desativar aquele Campo de Concentração "anexo" à Casa de Custódia e Tratamento de Taubaté, de onde surgiu a semente e as raízes do Comando, no meio de tantas lutas inglórias e a tantos sofrimentos atrozes.

O item 13 evidencia que um dos objetivos precípuos da organização do PCC foi, desde o início, promover segurança e autoproteção em face das condições carcerárias opressivas e do aumento da instabilidade, das pressões e da violência institucional, cujo marco foi o Massacre do Carandiru. Neste sentido, a governança e a provisão de proteção (Skarbek, 2012) são elementos essenciais para compreender a origem e o crescimento do PCC nas prisões de São Paulo, num contexto de recrudescimento da violência institucional, de aumento do encarceramento - portanto, da superlotação - e de degradação das condições carcerárias.

As diretrizes que estão registradas no estatuto ficaram evidentes quando ocorreu a chamada megarrebelião protagonizada pelo PCC, em 2001, e que trazia como um dos principais pontos de reivindicação exatamente a desativação do anexo em pauta. Em menor escala, brotaram naquela mobilização, ímpar até então, de cerca de 30 unidades prisionais em revolta simultânea no estado, as denúncias de condições degradadas de encarceramento, de violências e arbitrariedades (Salla, 2007; Dias, 2013). Através da megarrebelião, o PCC exibiu um considerável domínio sobre a massa carcerária e uma ampla capacidade de enfrentamento das autoridades.

Ao acionar os referenciais legais e subjacentes a isso - apontar para as injustiças produzidas na organização prisional -, o PCC se apresentava como interlocutor "legítimo" por parte dos presos diante das autoridades, o que, ao longo do tempo, foi uma fonte de empoderamento do grupo. De um lado, o PCC vai levantar tais 
denúncias diante das autoridades e da sociedade em geral, buscando atuar como interlocutor na negociação da ordem interna das prisões; de outro, o estatuto parece ter sido escrito numa clara estratégia para assegurar a lealdade daqueles que são vinculados ao grupo, mas se encontram fora das prisões, para garantir que eles cooperem materialmente com os que estão presos e viabilizem até mesmo as fugas, estabelecendo um fluxo mais contínuo entre o dentro e o fora das prisões, como se verifica no item $4 \stackrel{0}{\circ}$ :

\begin{abstract}
$44^{\circ}$. A contribuição daqueles que estão em Liberdade com os irmãos dentro da prisão através de advogados, dinheiro, ajuda aos familiares e ação de resgate.
\end{abstract}

Ficavam sob ameaça de morte os parceiros no crime que estavam fora da prisão e não colaborassem com os que estavam atrás das grades. Ameaça que revela o padrão de regramento produzido nas relações estabelecidas interna e externamente. Expressa também a lealdade produzida - e requerida, nesta ordenação das relações sociais - a partir da experiência comum do encarceramento (Jacobs, 1974; Philips, 2012), através do compartilhamento do sofrimento e do sentimento de injustiça. Lealdade que seria tecida e fortalecida também mediante o engajamento no "mundo do crime". É o que se observa no item 7을

7‥ Aquele que estiver em Liberdade "bem estruturado" mas esquecer de contribuir com os irmãos que estão na cadeia, serão condenados à morte sem perdão.

Vários trabalhos apontam o elevado número de mortes que foram produzidas nas prisões paulistas na primeira década de existência do PCC (Dias, 2013). De fato, a análise das normas do primeiro estatuto é bastante coerente com a forma de atuação da facção, notadamente quanto ao uso da violência física que caracterizou este período. O estatuto traz uma clara preocupação de assegurar a obediência da massa carcerária e dos membros do grupo à liderança. Além de apelar para a união em torno das adversas condições de encarceramento, dois outros aspectos se colocam: são estabelecidas as rotinas e as formas de comportamento a serem obedecidas, revestidas por um tom moral e também de lealdade ao "Partido" e a filiação ao mundo do crime, que ficará mais evidente no segundo estatuto que se verá adiante. Assim,

8‥ Os integrantes do Partido têm que dar bom exemplo a ser seguidos e por isso o Partido não admite que haja assalto, estupro e extorsão dentro do Sistema.

9‥ O partido não admite mentiras, traição, inveja, cobiça, calúnia, egoísmo, interesse pessoal, mas sim a verdade, a fidelidade, a 
hombridade, a solidariedade e o interesse como ao Bem de todos, porque somos um por todos e todos por um.

Em outros itens do estatuto, apela-se para a fidelidade, para o consenso e não são permitidas dissidências, discórdias entre os presos, nem se tolera o questionamento das lideranças. Na história prisional paulista, ao longo dos anos 1990 e 2000, tais diretrizes correram paralelamente às práticas violentas do grupo de aniquilar ou neutralizar os presos dissidentes e os grupos inimigos, numa escalada de rebeliões e de mortes (Dias, 2013; Adorno \& Salla, 2007).

Esse primeiro estatuto, além de uma série de propostas para organizar os presos, traz diretrizes para controlar as atividades criminosas fora dos muros da prisão. Essa lógica de atuação no mundo do crime ainda se apresenta no estatuto com a sugestão de união com o Comando Vermelho do Rio de Janeiro e de disseminação do grupo pelo Brasil. De certo modo, alguns desses traços revelam um momento da história do PCC em que busca consolidar o seu poder dentro do sistema prisional paulista, controlar atividades criminais fora das prisões e alcançar uma dimensão nacional - o que viria a se concretizar na sequência, produzindo alianças e rupturas com grupos de outros Estados (Manso \& Dias, 2018).

Em 2001, com a megarrebelião, a hegemonia do PCC junto à massa carcerária parece consolidada. Mas, ao mesmo tempo, desencadeou a criação do Regime Disciplinar Diferenciado (RDD), em 2003, como estratégia das autoridades para tentar neutralizar o grupo (Dias, 2009). O que deu resultado limitado pois, em 2006, o PCC promoveu no estado de São Paulo, sobretudo na capital, uma série de incêndios a ônibus, atentados a bancos e a outros estabelecimentos comerciais, assassinatos de policiais e agentes penitenciários. Além disso, 74 unidades prisionais se rebelaram de forma sucessiva, num espaço de quatro dias. Novamente, o PCC mostrava ampla capacidade de mobilização, agora explicitando a sua expansão para fora do sistema prisional, a partir da organização de ataques que acabaram espalhando o medo na população e paralisando a cidade de São Paulo por alguns dias (Adorno \& Salla, 2007; Adorno \& Dias, 2016). Houve uma série de confrontos das forças policiais e o PCC. A crise na área da segurança trouxe mudanças no comando da Secretaria da Administração Penitenciária e a nova gestão alterou em parte sua relação com as lideranças.

Uma vez conquistada a hegemonia sobre os presos e com a consolidação de seu poder sobre as atividades criminais dentro e fora das prisões, o PCC parece ter 
redefinido sua relação com a massa carcerária e com os integrantes do grupo, o que se pode constatar com o segundo estatuto, que passa a circular em 2011, ano em que o grupo comemorava - de maneira explícita, conforme pode ser observado no texto que acompanhava a disseminação do estatuto - a sua maioridade, ao completar 18 anos.

Esse novo estatuto - ainda em vigência - não por acaso é composto por 18 itens. Nele, percebe-se uma menor preocupação com os aspectos opressivos do sistema prisional - embora as injustiças continuem ocupando importante espaço em seu repertório. O deslocamento dessa narrativa para um segundo plano, sugere que o caráter denuncista em relação às condições severas de encarceramento destinava-se, essencialmente, a produzir a adesão dos presos e a despertar a sua percepção em relação às violências e às opressões sofridas dentro das prisões e a necessidade de união para enfrentar a opressão estatal. Na ocasião da formulação do segundo estatuto, o poder do grupo dentro das prisões está consolidado e cabe estabelecer as regras para a manutenção da hierarquia e a fidelidade dos membros, as formas, a conduta e as práticas que devem ser assumidas pelos membros do grupo. Conforme é possível compreender através da análise do segundo estatuto, tratava-se, mais de consolidar e expandir - para outros estados da federação - uma ordem estabelecida e de elencar algumas normas e diretrizes relacionadas às atividades econômicas, também bastante ampliadas e diversificadas 18 anos depois.

Um traço importante do segundo estatuto e que reflete as mudanças ocorridas no desenvolvimento do PCC diz respeito à sua expansão para fora do sistema prisional, delineando uma série de regras e eventuais punições para as violações às atividades econômicas ilícitas, aos compromissos financeiros de seus integrantes que estão fora da prisão e às ações de enfrentamento com as polícias.

Em meados da década de 1990, quando o primeiro estatuto foi escrito, o PCC estava ainda em fase de disputa, tanto no interior da massa carcerária como na relação com a administração, como protagonista relevante na negociação da ordem no interior das prisões. Com o segundo, evidencia-se a condição de poder consolidado na produção daquela ordem e a importância muito maior dada aos aspectos que dizem respeito às dinâmicas extraprisionais, embora não possamos perder de vista que a prisão permanece como lócus de atuação e centro de irradiação do PCC.

Quando se compara as instabilidades e rebeliões ocorridas nos anos 1990 e as atividades posteriores a 2001, nota-se que novos arranjos foram produzidos. Isso não significa que não tenham ocorrido instabilidades no âmbito do sistema prisional e 
2006 foi um exemplo disso. Mas fica evidente ali que o sistema de poder depois de 2001 se reconfigurou, adquirindo aspecto sistêmico, como se observou acima, tendo como elemento chave a hegemonia alcançada pelo PCC.

A maior parte dos artigos do segundo estatuto se constitui de diretrizes de conduta para os integrantes do grupo, dentro e fora das prisões, apelando fortemente para a união e lealdade à hierarquia. Não é possível deixar de apontar o paradoxo do estatuto neste sentido, uma vez que, em sua narrativa, os membros do PCC se referem à "abolição da hierarquia" e à "democratização" (Dias, 2013) como aspectos constitutivos da nova fase do grupo, que remete às mudanças em sua cúpula, ocorridas entre os anos 2003 e 2004. E, de fato, houve uma importante remodelação estrutural e organizacional marcada pela descentralização econômica e política. O PCC passou a acionar mecanismos decisórios coletivos, retirando de indivíduos isolados a prerrogativa de impor punições severas e instituiu o "debate" como instrumento de deliberação, envolvendo acusação, defesa e testemunhas e a adoção de punições proporcionais à gravidade da violação das normas (Feltran, 2010; Silvestre, 2018). Estes procedimentos, associados à própria hegemonia do PCC em São Paulo, efetivamente produziram efeitos importantes na dinâmica criminal do estado, através da estrita regulação dos homicídios e, em consequência, de sua expressiva redução (Dias, 2013; Feltran, 2018; Telles \& Hirata, 2010; Adorno, Dias \& Nery, 2016; Willis, 2015).

Nesse segundo estatuto, a partir da condição consolidada do grupo e hegemônica sobre os presos, suas lideranças passariam a ter um papel de maior relevância na produção da ordem nas prisões, tanto em relação às autoridades como em relação à massa carcerária. Assim, são mais numerosas as referências a procedimentos que envolvem os postos hierárquicos do grupo - sintonias - tanto para a apresentação de problemas por parte dos membros bem como na condição de instâncias decisórias. Menciona-se também que as sintonias são referências do grupo nos bairros, deixando evidente que a hierarquia dentro do mundo prisional também tem articulações com o lado de fora das prisões, tal como mostra o item 4ํㅡㄹ transcrito a seguir:

$4^{\circ}$. Aquele integrante que for para rua tem a obrigação de manter o contato com a sintonia da sua quebrada ou da quebrada que o mesmo estiver. Estar sempre à disposição do Comando, a Organização necessita do empenho e da união de todos os integrantes. Deixamos claro que não somos sócios de um clube e sim integrantes de uma Organização Criminosa, que luta contra as opressões e as injustiças que surgem no dia a dia e tenta nos afetar. Sendo assim, o Comando não admite acomodações e fraquezas. 
Um traço ainda importante desse segundo estatuto é a radicalização de sua identidade como organização criminosa. Já nesse item acima fica explicitada essa ten-

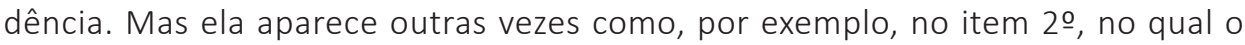
objetivo da organização é a luta pela "paz, justiça, liberdade, igualdade e união, visando o crescimento da nossa organização respeitando sempre a ética do crime".

A mesma adesão ao mundo do crime aparece no item 70 em relação à obrigação dos integrantes de ajudarem nas despesas com advogados, diversos auxílios (remédios, cestas básicas), transportes de familiares para visitas etc., mas também "na estrutura da luta contra nossos inimigos, entre várias situações que fortalecem nossa cauza (sic), ou seja o crime fortalece o crime, esta é a ideologia".

Importante ressaltar que a ideia de que "o crime fortalece o crime" irá aparecer em diversos outros documentos, cartas e comunicações do PCC, evidenciando o comprometimento em torno de uma identidade que se afirma não apenas no compartilhamento de uma mesma experiência - de relação com o sistema de justiça criminal, notadamente as polícias e as prisões - mas que se conforma em torno da adesão a um modo de vida específico, que gira em torno do engajamento numa multiplicidade de práticas ilícitas e na acentuada oposição ao Estado, em especial à Polícia Militar e ao sistema prisional.

Enquanto no primeiro estatuto fica explícita a intenção de constituir uma aliança com o Comando Vermelho do Rio de Janeiro, no segundo fica registrado de forma clara que "o Comando não tem coligação com nenhuma facção" (item 13). Ao invés de estabelecer vínculos estreitos com alguns grupos, o PCC evidencia a prioridade comercial nas relações estabelecidas com eles, independente de eventuais diferenças ideológicas: "vivemos em harmonia com facções de outros estados".

Certo esgarçamento das relações entre CV e PCC pode ser notado de um para outro estatuto, entre os quais há um lapso temporal de aproximadamente 15 anos. Enquanto o primeiro documento produzido pelo PCC vislumbrava a possibilidade de uma união nacional do "crime", representada pela "coligação PCC-CV", o segundo estatuto coloca a prioridade muito mais nos acordos comerciais, com todos os grupos de outros estados, ao invés de alianças políticas estratégicas com um grupo específico. Também fica evidente que não há um necessário compartilhamento de valores e de formas de conduta entre o PCC e o CV.

O distanciamento e o esgarçamento da pretendida coligação entre os dois grupos ficaram evidentes, em 2016, quando se escancarou uma ruptura entre o PCC e o 
CV. Aparentemente, a ruptura decorreu em razão da intensificação das tensões e de conflitos presentes na dinâmica competitiva própria dos mercados ilícitos e como resultado da pretensão de nacionalização de ambos os grupos (Manso \& Dias, 2017; 2018). Neste sentido, tanto o PCC quanto o CV adotaram estratégias de expansão para praticamente todos estados brasileiros, seja através das prisões, do mercado varejista da droga ou dos assaltos a bancos e a carros-fortes. Para tanto, ambos - com maior proeminência do PCC, mais organizado e mais estruturado - buscaram aproximar-se dos grupos locais, presentes em todos os estados, seja através de alianças e parcerias, seja através da absorção destes grupos e de sua incorporação aos grupos maiores ${ }^{17}$.

As ressonâncias dessa fratura nas alianças entre os dois grupos foram significativas em termos da ordem prisional nos diversos estados brasileiros. Em escala nacional, as prisões passaram por uma adaptação ao novo cenário de conflito entre essas duas facções. Foram intensas as remoções de presos de um presídio para outro para seu isolamento do convívio com os membros das facções inimigas. Mas isso não impediu que, em janeiro de 2017, três grandes chacinas de presos - uma no Amazonas, uma em Roraima e outra no Rio Grande do Norte, com 64, 33 e 26 mortos, respectivamente - exibissem o colapso da ordem prisional não assegurada pelas autoridades nem contida pelas facções (Manso \& Dias, 2018).

Em parte, esses acontecimentos refletem um posicionamento contido no segundo estatuto de ampliação do PCC no mundo do crime e nas prisões pelo Brasil, prevendo não apenas a presença de presos de facção de outros estados em São Paulo, mas também a de presos do PCC em outros estados.

Vale dizer que há muitas outras questões interessantes dos estatutos para serem abordadas - tanto nos trechos que foram aqui transcritos como em outros itens. Contudo, optou-se por manter o foco do texto principalmente na discussão sobre a construção da ordem prisional. E, neste sentido, os dois estatutos do PCC, distantes entre si mais de uma década, são pistas importantes para compreendermos as conformações da ordem prisional nos dois momentos em que são produzidos e difundidos e que refletem os contextos singulares a partir dos quais eles emergem. Refletem as perspectivas, os objetivos, os discursos e as práticas que, ao mesmo tempo, indicam continuidade e descontinuidade, permanências e mudanças, estabilidades e rupturas nas dinâmicas prisionais.
17. Sobre a ruptura entre o PCC e o CV, ver: <http:// www.bbc.com/ portuguese/ brasil-37663153>. 


\section{Algumas considerações}

A reflexão desenvolvida acima e a análise preliminar dos dois estatutos do PCC permitem compreender parte da história deste grupo, sublinhando mudanças e persistências tanto no que diz respeito ao repertório de ideias que conforma e justifica a sua atuação, quanto no que tange às dinâmicas engendradas pelas relações estabelecidas entre presos/criminosos em geral e entre estes e os atores institucionais, sobretudo as polícias e a administração prisional.

Com isso, a emergência do PCC significou a redefinição das relações produtoras e mantenedoras da ordem nas prisões, a partir de meados da década de 1990. Houve uma recomposição que se deu não apenas nas negociações locais com as autoridades, mas um novo tipo de relação entre o grupo e a massa carcerária. Nesse sentido, uma questão ainda a ser aprofundada diz respeito ao fato de o PCC ter se tornado ator político cujo raio de ação extrapola as unidades prisionais locais e adquire um caráter sistêmico. Seu espraiamento se deu por quase todo o sistema prisional paulista, com quase 200 unidades, e mesmo para outros estados, onde produziu uma série de efeitos, alguns dos quais sugerem justamente a desestabilização de ordens locais, rupturas e tensionamentos.

No caso que apresentamos, a ordem - ou as ordens prisionais, como se refere Carrabine (2005) - não é negociada apenas pelo jogo dos grupos e atores locais, mas recebe a injunção desse ator que tanto interfere nas ações das autoridades, assim como no posicionamento dos presos. Essa negociação da ordem tem, portanto, um cunho mais ampliado, o que, em relação à literatura existente, parece ser inovador para problematizar a questão das formas de dominação e legitimidade nas unidades prisionais, uma vez que, no caso do PCC, a ordem prisional se produz num nível supralocal. A análise dos estatutos permite aprofundar essa reflexão através das diretrizes homogêneas válidas para todos os contextos regulados, de alguma forma, pelo documento, ou seja, em que a ordem local se constitua através das diretrizes do PCC.

Assim, para a massa dos presos existe o espectro legal que consiste em fundamento para a legitimidade, para a aceitação da ordem (além das negociações e outras acomodações), mas a ordem tem para eles um componente que é também o regramento do PCC, formal e informal, que se impõe, que demanda lealdades, compromissos, que é ameaça, que é coercitivo, que sanciona os comportamentos. Neste sentido, trata-se de levar ao paroxismo a reciprocidade forçada, derivada do vácuo de poder estatal nas prisões provocado pela superlotação e pelo déficit de funcionários (Darke, 2013). 
Ou seja, se a produção da ordem no espaço prisional não é em si um elemento novo e é constitutiva da existência das prisões, a dinâmica engendrada pelo PCC - expressa nos dois estatutos analisados neste texto -, sugere que a maior extensão, os novos contornos, a maior perenidade e uniformidade na ordem produzida no contexto prisional paulista alavancaram transformações sociais e políticas que redefiniriam as relações entre os presos e as relações entre esses e a administração prisional.

Um campo promissor de pesquisa se abre, portanto, com o cenário prisional paulista depois de 2001, onde os elementos essenciais da produção da ordem são: a ameaça de uso do RDD sobretudo para as lideranças do PCC; ao mesmo tempo, as unidades prisionais lotadas ou superlotadas não explodem em movimentos de revolta apenas em razão das sanções legais disponíveis, mas por efeito de processos de negociação da ordem que envolvem as orientações do PCC para as unidades prisionais; há também, nesse tabuleiro, a existência da unidade de Presidente Wenceslau II, que concentra uma parcela significativa das lideranças do grupo, num regime prisional que não apresenta os rigores do RDD e que parece ter um papel fundamental na negociação da ordem prisional; o sistema penitenciário federal cuja importância nas dinâmicas de movimentação de presos cujo cumprimento de pena ocorre em São Paulo tem aumentado.

A hegemonia do PCC e sua consolidação no sistema prisional de São Paulo apresentam um dos efeitos paradoxais mais importantes, cujo entendimento ainda requer discussão e reflexão: de um lado, o PCC se apresenta como ator político com capacidade de mobilizar uma ação articulada em quase todo o sistema prisional, ameaçando, com isso, politicamente as autoridades estaduais; por outro lado, acaba privilegiando formas de acomodação e de negociação em que as rupturas da ordem tornam-se cada vez mais raras. Ou seja, ao mesmo tempo em que o PCC demonstra sua capacidade de desestabilizar o gigantesco sistema prisional paulista, são mais escassas as rupturas locais da ordem, mesmo com o agravamento das condições de encarceramento em parte considerável das unidades prisionais pertencentes a esse sistema.

Isso não significa que a administração não adote medidas de gestão do cotidiano prisional que impliquem ameaças de transferência, corte de regalias, segregação de presos no seguro etc. Porém, todas essas medidas, por vezes de caráter local, parecem acomodar-se ou diluir-se numa trama de relações, num pacto não formal de maior envergadura que produz uma ordem que acomoda em boa parte os interesses da administração e das lideranças do grupo. 
Por fim, se a legitimidade nas prisões é algo difícil de se alcançar, por todos os motivos expostos neste texto, a experiência prisional paulista (e por que não dizer, brasileira) traz um componente ainda mais perverso para a massa de presos "desfiliada", avulsa. A manutenção da ordem prisional construída e mantida a partir de formas de acomodação absolutamente obscuras, envolvendo a administração prisional e os líderes do PCC, implica impor sobre a massa carcerária a necessidade de suportar condições subumanas de encarceramento como, por exemplo, a convivência de 50, 60 presos numa cela com capacidade para 12, além de escassez de alimentação, produtos de higiene pessoal etc. Neste sentido, na medida em que se consolida como ator político no cenário prisional paulista, paradoxalmente, o PCC passa a privilegiar outros elementos como condição fundamental para a manutenção da ordem, de forma que a luta contra as péssimas condições de encarceramento - que fundamentou a sua criação - permanece elemento central na construção discursiva e narrativa, mas passa a figurar num segundo plano em termos das estratégias políticas e concretas através das quais se conforma a ordem prisional em São Paulo.

Não obstante essa polarização, as fraturas na ordem interna - como as rebeliões - podem ser consideradas de pequena monta no sistema prisional paulista nos últimos anos, colocando o desafio de aprofundar analiticamente como se dá esse processo de construção da ordem nesse contexto, que tipo de ordem deriva dessa polarização, tanto no plano local como em relação ao sistema prisional como um todo.

\section{Referências}

ADORNO, Sérgio; DIAS, Camila N. Dias. Fronteiras em mutação: um novo paradigma na sociologia das prisões? In: PIORE, Mari del; MULLER, Angélica (Orgs.). História dos crimes e da violência no Brasil, p. 433-459. São Paulo: Editora Unesp, 2017.

—. Cronologia dos "Ataques de 2006" e a nova configuração de poder nas prisões na última década. Revista Brasileira de Segurança Pública, v. 10, n. 2, p. 118132, 2016.

ADORNO, Sérgio; DIAS, Camila N.; NERY, Marcelo. A cidade e a dinâmica da violência. In: KOWARICK, Lúcio; FRÚGOLI Heitor (Orgs.). Pluralidade urbana em São Paulo, p. 381-410. São Paulo: Editora 34, 2016.

ADORNO, Sérgio; SALLA, Fernando. Criminalidade organizada nas prisões e os ataques do PCC. Revista Estudos Avançados, v. 61, n. 3, p. 7-29, 2007. 
ALVAREZ, Marcos César; SALLA, Fernando; DIAS, Camila Nunes. Das Comissões de Solidariedade ao Primeiro Comando da Capital em São Paulo. Tempo Social, v. 25, n. 1, p. 61-82, 2013.

BATISTA, Analía Soria. Estado e controle nas prisões. Caderno CRH, v. 56, p. 399-410, 2009.

BEETHAM, D. The legitimation of power. London: MacMillan, 1991.

CARRABINE, Eamonn. Prison riots, social order and the problem of legitimacy. British Journal of Criminology, v. 45, n. 6, p. 896-910, first published online June 1, 2005.

CLEMMER, Donald. The prison community. New York: Holt, Rinehart \& Winston, 1958 [1940].

COELHO, Edmundo Campos. A oficina do Diabo: crise e conflitos no sistema penitenciário do Rio de Janeiro. Rio de Janeiro: Espaço e Tempo/luperj, 1987.

DARKE, Sacha. Managing without guards in a Brazilian police lockup. Focaal - Journal of Global and Historical Anthropology, v. 68, p. 55-67, 2014.

Inmate Governance in Brazilian Prisons. The Howard Journal, v. 52, n. 3, p. 272-284, Jul. 2013.

DIAS, Camila N. Encarceramento, seletividade e opressão: a "crise carcerária" como projeto político. Análise. Brasil: Friedrich-Ebert-Stiftung (FES), 2017.

2013

PCC: hegemonia nas prisões e monopólio da violência. São Paulo: Saraiva,

—. Efeitos simbólicos e práticos do regime disciplinar diferenciado (RDD) na dinâmica prisional. Revista Brasileira de Segurança Pública, Ano 3, n. 5, p. 128-144, Ago./Set. 2009.

DIAS, C. et alii. O encarceramento em massa como política pública de segurança: efeitos perversos e consequências nefastas. Teoria \& Debate, Jun. 2015. Disponível em: <http://www.teoriaedebate.org.br/materias/nacional/o-encarceramento-em-massa--como-politica-de-seguranca?page=full>. Acesso em: 17 Jul. 2017.

- A prática de execuções na região metropolitana de São Paulo na crise de 2012: um estudo de caso. Revista Brasileira de Segurança Pública, v. 9. n. 2, p. 160179, Ago./Set. 2015a. 
DIAS, Camila Caldeira Nunes; SALLA, Fernando. Organized crime in Brazilian prisons: the example of the PCC. International Journal of Criminology and Sociology, v. 2, p. 397-408, 2013. Disponível em: <http://www.lifescienceglobal.com/independent-journals/international-journal-of-criminology-and-sociology/volume-2?id=306>.

DILULIO JR., John J. Governing prisons: a comparative study of correctional management. New York: The Free Press, 1990.

FELTRAN, Gabriel. Irmãos: uma história do PCC. São Paulo: Companhia das Letras, 2018.

- The management of violence on the periphery of São Paulo: a normative apparatus repertoire in the PCC era? Vibrant, v. 7, n. 2, p. 7-12, 2010.

GODOI, Rafael. Fluxos em cadeia: as prisões em São Paulo na virada dos tempos. São Paulo: Boitempo, 2017.

GÓES, Eda Maria. A recusa das grades: rebeliões nos presídios paulistas, 1982-1986. São Paulo: Instituto Brasileiro de Ciências Criminais, "Coleção Monografias", v. 54, 2009.

GOFFMAN, Ervin. Manicômios, prisões e conventos. São Paulo: Perspectiva, 1974 [1961].

HOLSTON, James. Dangerous spaces of citizenship gang talk, rights talk and rule of law in Brazil. Planning Theory, v. 8, n. 1, p. 12-31, 2009.

JACOBS, James B. Stateville - the penitentiary in mass society. Chicago (IL): The University of Chicago Press, 1977.

—. Street gangs behind bars. Social Problems, v. 21, n. 3, p. 395-409, 1974.

JOZINO, Josmar. Casadas com o crime. São Paulo: Letras do Brasil, 2008.

KING, Roy D.; MCDERMONT, Kathkeen. "My geranium is subversive": some notes on the management of trouble in prison. The British Journal of Sociology, v. 41, n. 4, p. 445-471, 1990.

LIEBLING, Alison. Distinctions and distinctiveness in the work of prison officers: Legitimacy and authority revisited. European Journal of Criminology, v. 8, n. 6, p. 484499, 2011.

MACCORMICK, Austin H. Behind the prison riots. The Annals of American Academy of Political and Social Science, v. 293, p.17-27, 1954. 
MANSO, Bruno P; DIAS, Camila N. A guerra-ascensão do PCC e o mundo do crime no Brasil. São Paulo: Todavia, 2018.

PCC, sistema prisional e gestão do novo mundo do crime no Brasil. Revista Brasileira de Segurança Pública, v. 11, n. 2, p. 10-29, Ago./Set. 2017.

MATHIESEN, Thomas. The sociology of prisons: problems for future research. The British Journal of Sociology, v. 17, n. 4, p. 360-379, 1966.

PHILLIPS, Coretta. "It ain't nothing like America with the bloods and the crips": gangs narratives inside two English prisons. Punishment \& Society, v. 14, n. 1, p. 51-68, 2012.

RAMALHO, José Ricardo. Mundo do crime: a ordem pelo avesso. Rio de Janeiro: Graal, 1979.

RUOTTI, Caren. Pretensão de legitimidade do PCC: justificação e reconhecimento de suas práticas nas periferias da cidade de São Paulo. Tese (Doutorado em Sociologia) - Faculdade de Filosofia, Letras e Ciências Humanas, Universidade de São Paulo, São Paulo, 2016. Doi:10.11606/T.8.2016.tde-24112016-130450. Acesso em: 22 Mar. 2019.

SALLA, Fernando. Considerações sociológicas sobre o crime organizado no Brasil. Revista Brasileira de Ciências Criminais, v. 71, p. 364-390, 2008.

De Montoro a Lembo: as políticas penitenciárias de São Paulo. Revista Brasileira de Segurança Pública, v. 1, n. 1, p.72-90, 2007.

- As rebeliões nas prisões: novos significados a partir da experiência brasileira. Sociologias, v. 16, p. 274-304, 2006.

SALLA, Fernando; NUNES, Camila. Controle Disciplinar e relações de poder nas prisões em São Paulo. Paper apresentado no XXXV Encontro Anual da Anpocs, 24 a 28 de outubro de 2011, no Grupo de Trabalho GT 38 - Violência, criminalidade e punição no Brasil. Disponível em: <http://www.anpocs.org.br/portal/index.php?option=com_wrapper\&Itemid=94>.

SALLA, Fernando; DIAS, Camila Caldeira Nunes; SILVESTRE, Giane. Políticas penitenciárias e as facções criminosas: uma análise do regime disciplinar diferenciado (RDD) e outras medidas administrativas de controle da população carcerária. Estudos de Sociologia, v. 17, n. 33, p. 333-351, 2012. Disponível em: <http://seer.fclar. unesp.br/estudos/article/view/5419/4328>. 
SILVESTRE, Giane. Controle do crime e seus operadores: política e segurança em São Paulo. São Paulo: Annablume, 2018.

- Dias de visita: uma sociologia da punição e das prisões. São Paulo: Alameda Casa Editorial, 2012.

SKARBEK, David. Covenants without the sword? Comparing prison self-governance globally. American Political Science Review, v. 110, n. 4, p. 845-862, 2016.

- Prisons gangs, norms, and organizations. Journal of Economic Behavior \& Organization, v. 82, p. 92-109, 2012.

SOUZA, Percival. A prisão: histórias dos homens que vivem no maior presídio do mundo. São Paulo: Alfa-Omega, 1977.

—. O prisioneiro da grade de ferro. São Paulo: Traço, 1983.

SPARKS, J. R.; BOTTOMS, A. E. Legitimacy and order in prisons. The British Journal of Sociology, v. 46, n. 1, p. 45-62, 1995.

SYKES, Gresham M. The society of captives: a study of a maximum security prison. New Jersey, Princeton University Press, 1974 [1958].

TEIXEIRA, Alessandra. Prisões da exceção: política penal e penitenciária no Brasil contemporâneo. Curitiba: Juruá, 2009.

TELLES, Vera da Silva; HIRATA, Daniel. Ilegalismos e jogos de poder em São Paulo. Tempo Social, v. 22, p. 39-59, 2010.

TYLER, T. R. Why people obey the law. New Haven (CT): Yale University Press, 1991.

USEEM, Bert; KIMBALLA, Peter A. States of siege: U. S. prison riots, 1971-1986. New York: Oxford University Press, 1991.

WILLIS, Graham D. The killing consensus: police, organized crime, and the regulation of life and death in urban Brazil. Oakland (CA): University of California Press, 2015. 